\title{
Limonene, (+)-
}

National Cancer Institute

\section{Source}

National Cancer Institute. Limonene, (+)-. NCI Thesaurus. Code C61714.

An oral dietary supplement containing a natural cyclic monoterpene and major

component of the oil extracted from citrus peels with potential chemopreventive and antitumor activities. Although the mechanism of action has yet to be fully elucidated, limonene and its metabolites perillic acid, dihydroperillic acid, uroterpenol and limonene 1,2-diol may inhibit tumor growth through inhibition of p21-dependent signaling and may induce apoptosis via the induction of the transforming growth factor beta-signaling pathway. In addition, they inhibit post-translational modification of signal transduction proteins, resulting in G1 cell cycle arrest as well as differential expression of cell cycle- and apoptosis-related genes. 